\title{
A questionnaire-based study to comprehensively assess the status quo of rare disease patients in China
}

\section{Xuefeng Li}

Guangzhou Medical University

Meiling Liu

Guangzhou Medical University

Bingzhe Li

Oklahoma State University

Xiangyu Zhang

University of Minnesota

Shu Zhang

Kunming Medical University

\section{Zijuan Lu}

Tongji University

Jianyong Zhang

Jinhaishiji

Jincheng Zhou

Amgen Inc

Li Ou ( $D$ ouxxx045@umn.edu)

University of Minnesota Twin Cities https://orcid.org/0000-0002-7743-5649

\section{Research}

Keywords: rare disease, orphan drug, patient organizations, questionnaire

Posted Date: October 9th, 2020

DOI: https://doi.org/10.21203/rs.3.rs-88844/v1

License: (c) (i) This work is licensed under a Creative Commons Attribution 4.0 International License.

Read Full License 


\section{Abstract}

Background: There are over 16.8 million rare disease patients in China, representing a large community that should not be neglected. To provide a basis for policy-makers, a comprehensive analysis of the status quo, unmet needs, difficulty caused by the rare disease is essential.

Methods: Therefore, a questionnaire-based study of patients and care-givers was performed.

Findings: A total of 1,959 patients and care-givers participated, representing 104 rare diseases, such as lysosomal diseases, hemophilia, and muscular dystrophy. The diagnosis was delayed for $1.4 \pm 3.0$ years, and patients experienced $1.6 \pm 3.8$ misdiagnoses between $3.2 \pm 2.4$ hospitals. The hospitals where diagnoses made were highly concentrated in 10 large hospitals (43.8\%) and 5 big cities (42.1\%), indicating a significant inequality of medical resources. The disease often led to difficulty in social life, education, and employment, as well as financial burden that was seldom covered by medical insurance. A battery of standardized tests, including SF-36, PHQ-9, PHQ-15, GAD-7, and PSQI, demonstrated poor health status, depression, somatization, anxiety, and sleeping issues among both patients and care-givers $(p<0.05)$.

To examine the influence of age, disease type, and relationship to patients on the scores in these tests, statistical analysis with a general linear model was conducted. It was also shown that poor health, anxiety, depression, somatization, and sleeping problems were more prevalent in patients than in caregivers, and more prevalent in more severe diseases (e.g., hemophilia, Dravet) or undiagnosed than in other diseases.

Interpretations: This study identified the lack of rare disease awareness and legislative support as the major challenge to rare diseases in China, and makes key recommendations for policy-makers, including legislating orphan drug act, raising rare disease awareness, and protecting rights in education and employment.

\section{Introduction}

A rare disease is any disease that affects a relatively small number of people. There is no universal definition of rare diseases, and definitions vary in different countries. There are between $5,000-8,000$ rare diseases [1], affecting a total of 400 million patients worldwide [2]. Together, rare diseases affect approximately $6-10 \%$ of the population and $3-4 \%$ of births [3], thus rare diseases pose a significant challenge to the healthcare system. Approximately $80 \%$ of rare diseases are genetic, many of which are life-threatening [4]. Most rare disease patients are children, and $30 \%$ of patients die before age 5 [5]. Delayed diagnosis and misdiagnosis are common, resulting in inappropriate treatment and poor outcomes [6]. Approximately 95\% of rare diseases have no treatment options [5]. Even if treatments exist, the availability and affordability of treatment are often poor, especially in developing countries. Awareness and knowledge of rare diseases are often lacking, rendering many patients struggling to find 
adequate information. Consequently, the emotional, psychological, and financial impact of a rare disease on patients and care-givers is also considerable.

There is still no official definition of rare diseases in China; therefore, the total number of rare disease patients in China is unknown. It was previously estimated to be 16.8 million [7]. However, this may be a significant underestimate considering the population of 1.4 billion. Further, there lacks legislation or medical insurance coverage of rare diseases, resulting in low interest in orphan drug development of the pharmaceutical industry. The rare disease field is largely underdeveloped due to the lack of rare disease awareness, legislation, pharmaceutical development, and insurance coverage in China. It is essential to have a comprehensive understanding of this field to provide a basis for legislation. Therefore, this study aims to assess the status quo, unmet needs, recommendations of patients and care-givers. A questionnaire composed of 116 questions including standardized tests (SF-36, PHQ-9, PHQ-15, GAD-7, and PSQI) was sent to patients and care-givers. Key recommendations to support patients, motivate orphan drug development, and improve rare disease awareness, are made based on the results obtains. This is the first large-scale study to assess patients and care-givers of rare diseases in China.

\section{Materials And Methods}

\section{Ethics statement}

The study was approved by the Institutional Ethics Committee of Guangzhou Medical University. Potential participants were invited, and only those who signed the informed consent participated in this study between March and May 2020. A questionnaire for patients and care-givers, composed of 116 questions, were designed in Chinese. Participants were invited through advertisements on social media and websites. All the participants acknowledged; 1 ) that they will participate in this study anonymously;

2) that they can decline to answer any of the questions; 3 ) that they can quit the study at any time; 4) that the results will be published in a scientific journal without seeking their approval of the manuscript; and 5) that they will not be paid for participating in this study.

\section{Assessment Instruments}

The Short Form (36) Health Survey is a 36-item, self-reported survey of health [8]. SF-36 includes 8 domains: physical function (PF), role limitations due to physical problems (RP), bodily pain (BP), general health (GH), vitality (VT), social function (SF), role limitations due to emotional problems (RE), mental health $(\mathrm{MH})$. The score of each domain ranges from 0 to 100, and a low score indicates poor health. The Pittsburgh Sleep Quality Index (PSQI) is a screening tool for sleeping difficulty. PSQI consists of 19 items that can be categorized into 7 domains, including subjective sleep quality (SQ), sleep latency (SL), sleep duration (SD), habitual sleep efficiency (SE), sleep disturbance (Dis), sleep medication use (SM), and daytime dysfunction (DD) [9]. The total score of PSQI ranges from 0 to 21, and a high score indicates poor sleep quality. Patient Health Questionnaire-9 (PHQ-9) is a 9-item screening tool for depression [10]. PHQ-9 measures the frequency of depression symptoms over the last 2 weeks. The total score of PHQ-9 ranges from 0 to 27 , and scores of $\geq 5, \geq 10$, and $\geq 15$, represent mild, moderate, and severe depression. 
PHQ-15 is a screening tool for somatization [11]. PHQ-15 measures the severity of individual somatic symptoms during the past 4 weeks. The total score of PHQ-15 ranges from 0 to 30 , and scores of $\geq 5$, $\geq 10, \geq 15$ represent mild, moderate, and severe somatization, respectively. Generalized Anxiety Disorder Scale (GAD-7) is a screening tool for anxiety [12]. Each item describes one of the typical anxiety symptoms and measures the frequency of each symptom over the past 2 weeks. The reliability and validity of the Chinese version of SF-36, PSQI, PHQ-9, PHQ-15, and GAD-7 have been confirmed [13-17].

\section{Data analysis}

SPSS 20.0 was used to analyze data, and a p value $<0.05$ (two-tailed tests) denotes statistical significance. The scores of SF-36, PHQ-9, PHQ-15, GAD-7, and PSQI largely met normal distribution, therefore, a general linear model was applied. For SF-36, PHQ-9, PHQ-15, GAD-7, and PSQI, only those who completed all questions of each test were included in the quantitative analysis. Mean \pm standard deviations and $95 \%$ confidence interval $(\mathrm{Cl})$ were used to describe continuous outcomes.

\section{Results}

\section{Demographic information}

A total of 1,959 individuals signed informed consent and participated in the questionnaire. The demographic information of participants is listed in Table 1. These participants represent 104 rare diseases and those undiagnosed. The average onset age is $36.8 \pm 85.1$ months, while the average diagnosis age is $56.5 \pm 110.0$ months ( $95 \% \mathrm{Cl} 51.6$ to 61.4 ). The diagnosis was delayed for $16.2 \pm 35.4$ months ( $95 \% \mathrm{Cl} 14.6$ to 17.8$)$. Interestingly, 497 patients (26.1\%) were diagnosed through newborn screening. When patients diagnosed through newborn screening was excluded, the diagnosis was delayed for $24.3 \pm 41.8$ months ( $95 \% \mathrm{Cl} 22.1$ to 26.5 ), with the onset age being $48.6 \pm 95.0$ months ( $95 \%$ $\mathrm{Cl} 43.6$ to 53.6 ), and diagnosis age being $77.9 \pm 122.7$ months ( $95 \% \mathrm{Cl} 71.5$ to 84.3 ). During the diagnosis odyssey, patients visited $3.2 \pm 2.4$ hospitals ( $95 \% \mathrm{Cl} 3.1$ to 3.3 ), and experienced $1.6 \pm 3.8$ misdiagnoses ( $95 \% \mathrm{Cl} 1.4$ to 1.8 ). A total of 1,770 participants provided information about 139 hospitals where the diagnosis was made. Hospitals diagnosed more than 20 participants of this study were listed in Fig. $1 \mathrm{~A}$. The top 10 hospitals on the list diagnosed 777 patients (43.8\% of total), and they were all located in big cities (Fig. 1B). The top 5 cities diagnosed a combined total of 745 patients (42.1\%). There is a clear inequality of medical resources in China. As shown in Fig. 1C, most respondents (79.0\%) believed that diagnosis helped to figure out treatment and management options, while 1,530 (78.6\%) believed that diagnosis helped to understand the disease cause and progression. Interestingly, 290 individuals (14.9\%) thought that diagnosis had negative impacts (depression, anxiety, guilt, denial, discrimination, and financial stress). As shown in Fig. 1D, 687 of 1,831 respondents (37.5\%) had received genetic counseling and believed it to be helpful, $146(8.0 \%)$ believed it to be not helpful, while $227(12.4 \%)$ believed it to be moderately very helpful. A total of 560 patients (30.6\%) had never received genetic counseling. Most respondents $(72.6 \%)$ believed that their doctors did not have sufficient information about rare diseases. Most respondents (82.1\%) deemed newborn screening to be extremely important. 
Table 1

Demographic information of participants of the questionnaire for patients and care-givers. Only provinces/districts with more than 100

participants were shown. Only diseases with more than 20 participants were shown. Mean \pm standard deviations.

\begin{tabular}{|c|c|}
\hline \multirow[t]{2}{*}{ Relationship } & Patients $(n=340,17.4 \%)$ \\
\hline & Care-givers $(n=1,599,81.6 \%)$ \\
\hline \multirow[t]{2}{*}{ Gender } & Male $(n=575,29.6 \%)$ \\
\hline & Female $(n=1,369,70.4 \%)$ \\
\hline \multirow[t]{3}{*}{ Age } & Respondents (33.9 \pm 7.4 years) \\
\hline & Patients (10.6 \pm 12.6 years) \\
\hline & Care-givers (34.4 \pm 6.7 years) \\
\hline \multirow[t]{8}{*}{ Locations } & Shandong $(n=164)$ \\
\hline & Sichuan $(n=144)$ \\
\hline & Hubei $(n=140)$ \\
\hline & Henan $(n=134)$ \\
\hline & Guangdong $(n=128)$ \\
\hline & Hunan $(n=109)$ \\
\hline & Beijing $(n=103)$ \\
\hline & Other $(n=999)$ \\
\hline \multirow[t]{10}{*}{ Disease } & $\mathrm{CAH}(\mathrm{n}=419)$ \\
\hline & $\mathrm{PKU}(\mathrm{n}=246)$ \\
\hline & Hemophilia $(n=243)$ \\
\hline & Dravet $(n=153)$ \\
\hline & DMD (158) \\
\hline & Neurofibromatosis $(n=69)$ \\
\hline & Pompe $(n=40)$ \\
\hline & MPS $(n=71)$ \\
\hline & $\mathrm{AHC}(\mathrm{n}=28)$ \\
\hline & Addison' disease $(n=26)$ \\
\hline
\end{tabular}




\begin{tabular}{|ll|}
\hline Relationship & Patients $(n=340,17.4 \%)$ \\
& SCA $(n=38)$ \\
& Undiagnosed $(n=193)$ \\
& Other $(n=275)$ \\
\hline
\end{tabular}

\section{Orphan Drugs And Medical Cost}

As shown in Fig. 2, most respondents (57.7\%) rated the availability of orphan drugs as extremely poor, and 456 individuals $(23.7 \%$ ) rated it as poor. As to the affordability of orphan drugs, most respondents $(72.3 \%)$ rated it as extremely poor $(43.0 \%)$ or poor $(29.3 \%)$. Most respondents $(50.4 \%)$ had spent $5-50 \%$ of their annual family income on the medical cost of rare diseases, 526 respondents $(27.7 \%)$ had spent $50-100 \%$ of income, and $231(12.2 \%)$ had spent $>100 \%$ of income. These results indicate that rare diseases caused a significant financial burden. As to the specific types of medical insurance, most respondents (59.6\%) had Basic Medical Insurance Systems for Urban and Rural Residents, 404 (20.8\%) had Medical/Social Insurance Program for Children, and 112 (5.8\%) had no medical insurance. However, only $0.8 \%(16 / 1,913)$ individuals had orphan drug costs fully covered by insurance, $50.2 \%$ individuals had partial coverage, while the medical cost of $48.1 \%$ individuals was not covered by insurance at all. Out of 1,936 respondents, 877 (45.3\%) recommended to implement special insurance program for rare diseases, 847 (43.8\%) recommended to include rare diseases into Critical Illness Insurance Program, a national medical insurance program. Only 8 individuals $(0.4 \%)$ believed that the current insurance system is sufficient. These results demonstrate that there lacks sufficient support from the medical insurance system.

\section{Difficulty In Life, Education, And Employment}

Patients and care-givers are also often disadvantaged in employment, education, and social life [18]. In this study, only $37.6 \%$ of respondents did not need any assistance, while the remaining $62.4 \%$ needed different levels of assistance. However, $83.0 \%$ of patients had no disability certificates, which are issued by the government to provide benefits and protection. Out of 1,830 respondents, 725 (39.8\%) found no available barrier-free facilities, and $490(26.9 \%)$ found very few such facilities. Only $61(3.4 \%)$ and 277 (15.2\%) believed that available barrier-free facilities could completely or largely meet the needs, respectively. Most respondents (59.7\%) had experienced difficulty in education. As to the main financial source of patients, $69.6 \%$ of respondents relied on the incomes of their family members, and only 215 $(11.4 \%)$ relied on their own incomes. It was estimated that $61 \%$ of rare disease patients and care-givers in Europe had experienced interruptions in their professional activities [19]. In China, this situation seemed to be even more severe. Only $88(4.7 \%), 23(1.2 \%)$ and 35 (3.5\%) of patients had full-time, part-time jobs, or free-lancers, respectively. A total of 823 patients (43.8\%) were children or retired, $549(29.2 \%)$ were in college and continuing education, and 333 (17.7\%) were unemployed. Most respondents $(62.0 \%)$ believed that patients had experienced difficulty in finding jobs. As to the specific challenges in finding jobs, 340 
out of 1,024 respondents (33.2\%) attributed it to 'insufficient opportunities', 264 (25.8\%) chose 'discrimination', 233 (22.8\%) chose 'lack of skillsets', and 178 (17.4\%) chose 'lack of special employment agencies'.

\section{Needs And Activities}

Most respondents (75.4\%) had joined patient organizations. As shown in Fig. S1 A, among these individuals, 1,351 (94.1\%) listed 'communicate disease information' as a major reason to join such organizations, and 1,000 (69.6\%) mentioned 'obtain support and guidance from organizations'. Out of 1,889 respondents, $693(36.7 \%)$ rated the performance of patient organizations as 'very good, but can be improved', and 687 (36.4\%) rated them as 'extremely good', indicating a general approval of the work of patient organizations. The 968 individuals who did not rate patient organizations as 'extremely good' were questioned on how to improve the work of patient organizations (Fig. S1B). A total of 616 individuals (63.6\%) suggested these organizations to 'obtain more philanthropic support', 614 (63.4\%) suggested to 'provide more disease-related information and guidance', 601 (62.1\%) suggested 'advocacy for legislations', 579 (59.8\%) suggested 'raise rare disease awareness', 424 (43.8\%) suggested 'protect patient rights', and 267 (27.6\%) suggested 'maintain an equal and respectful environment for communication'. The information needs of patients and care-givers were also assessed (Fig. S1C). Out of 1,923 respondents, 1,538 (80.0\%) selected information about 'treatment', 1,429 (74.3\%) selected 'research progress', 1,282 (66.7\%) selected 'medical insurance', and 1,089 (56.6\%) selected 'contact information of experts'. Currently, most respondents (70.1\%) obtained relevant information through social media, 1,074 (54.8\%) through physicians, $864(44.1 \%)$ through websites, 675 (34.5\%) through patient meetings. As to the preference of information source, 1,419 out of 1,911 respondents $(74.3 \%)$ mentioned social media, $1,334(69.8 \%)$ selected physicians, and 1,207 (63.2\%) selected websites. There is clearly a discrepancy between information obtained and information the patient hoped to obtain from physicians. Participants also made recommendations to policy-makers on how to help rare disease patients (Fig. S1D). Out of 1,924 respondents, 1,725 (89.7\%) recommended 'support orphan drug development', and 1,681 (87.4\%) recommended 'appropriate medical insurance for rare disease patients'.

\section{Quality Of Life}

A battery of standardized surveys was employed to assess the quality of life, health status, and psychological status of patients and care-givers. First, as to SF-36, a health assessment tool, patients and care-givers had remarkably lower scores in all domains than healthy populations (Table 2). As to PHQ-9, a depression screening tool, patients had an average score of 12.1 (95\% Cl: 11.4 to 12.8), while care-givers had an average score of 9.5 (95\% Cl: 9.1 to 9.9) (Table 3). The scores of patients and care-givers were higher than normative values and were in the category of moderate and mild depression, respectively. As to GAD-7, an anxiety screening tool, patients had an average score of 9.0 ( $95 \% \mathrm{Cl}: 8.3$ to 9.6 ), and caregivers had an average score of 7.7 (95\% Cl: 7.4 to 8.0) (Table 3). Both patients and care-givers were in the category of mild anxiety, and were significantly higher than normative values from the healthy population. As to PHQ-15, a somatization screening tool, the average score of patients was 10.3 (95\% Cl: 
9.6 to 11.0), higher than the cut-off value of medium somatic symptom severity. The average score of care-givers was 8.1 (95\% Cl: 7.6 to 8.5). The scores of patients and care-givers were significantly higher than normative values in healthy populations. As to PSQI, a sleeping difficulty screening tool, the average score of patients and care-givers were 8.5 (95\% Cl: 8.0, 8.9) and 6.9 (95\% Cl: 6.7, 7.2), respectively. These scores were also higher than normative values, indicating severe sleeping problems. There was a significant correlation between all seven domains of PSQI (Table S1), and Cronbach's alpha was 0.798, indicating a good internal consistency. Together, these results demonstrate that the disease burden led to poor health, anxiety, depression, somatization, and sleeping problems in patients and care-givers.

Table 2

Scores of patients and care-givers in SF-36.

\begin{tabular}{|c|c|c|c|c|c|c|c|c|}
\hline & Patients & & Care-giver & & Hubei 27 & Shanghai ${ }^{28}$ & USA $^{29}$ & Canada $^{30}$ \\
\hline & $\mathrm{n}=259$ & & $n=1,061$ & & $n=2,249$ & $n=919$ & $\begin{array}{l}n= \\
2,474\end{array}$ & $n=9,423$ \\
\hline & $\begin{array}{l}\text { Mean } \\
\text { (SD) }\end{array}$ & $95 \% \mathrm{Cl}$ & $\begin{array}{l}\text { Mean } \\
\text { (SD) }\end{array}$ & $95 \% \mathrm{Cl}$ & $\begin{array}{l}\text { Mean } \\
\text { (SD) }\end{array}$ & Mean (SD) & $\begin{array}{l}\text { Mean } \\
\text { (SD) }\end{array}$ & $\begin{array}{l}\text { Mean } \\
\text { (SD) }\end{array}$ \\
\hline PF & $\begin{array}{l}52.5 \\
(34.8)\end{array}$ & $\begin{array}{l}48.3 \\
56.6\end{array}$ & $\begin{array}{l}70.2 \\
(31.1)\end{array}$ & $\begin{array}{l}68.4 \\
72.1\end{array}$ & $\begin{array}{l}90.6 \\
(15.4)\end{array}$ & $89.7(14.8)$ & $\begin{array}{l}84.2 \\
(23.3)\end{array}$ & $\begin{array}{l}85.8 \\
(20.0)\end{array}$ \\
\hline RP & $\begin{array}{l}26.8 \\
(39.6)\end{array}$ & $\begin{array}{l}21.0 \\
31.6\end{array}$ & $\begin{array}{l}57.6 \\
(46.0)\end{array}$ & $\begin{array}{l}55.8 \\
60.3\end{array}$ & $\begin{array}{l}79.5 \\
(34.7)\end{array}$ & $92.8(22.6)$ & $\begin{array}{l}81.0 \\
(34.0)\end{array}$ & $\begin{array}{l}82.1 \\
(33.2)\end{array}$ \\
\hline BP & $\begin{array}{l}65.5 \\
(32.0)\end{array}$ & $\begin{array}{l}\text { 61.6, } \\
69.3\end{array}$ & $\begin{array}{l}82.7 \\
(28.1)\end{array}$ & $\begin{array}{l}81.0, \\
84.4\end{array}$ & $\begin{array}{l}85.6 \\
(18.4)\end{array}$ & $94.6(13.8)$ & $\begin{array}{l}75.2 \\
(23.7)\end{array}$ & $\begin{array}{l}75.6 \\
(23.0)\end{array}$ \\
\hline $\mathrm{GH}$ & $\begin{array}{l}32.6 \\
(21.3)\end{array}$ & $\begin{array}{l}30.0 \\
35.1\end{array}$ & $\begin{array}{l}46.2 \\
(22.7)\end{array}$ & $\begin{array}{l}44.9 \\
47.6\end{array}$ & $\begin{array}{l}69.6 \\
(21.3)\end{array}$ & $68.8(19.4)$ & $\begin{array}{l}72.0 \\
(20.3)\end{array}$ & $\begin{array}{l}77.0 \\
(17.7)\end{array}$ \\
\hline VT & $\begin{array}{l}35.6 \\
(22.5)\end{array}$ & $\begin{array}{l}32.9 \\
38.3\end{array}$ & $\begin{array}{l}46.2 \\
(22.7)\end{array}$ & $\begin{array}{l}44.9 \\
47.6\end{array}$ & $\begin{array}{l}70.3 \\
(17.1)\end{array}$ & 71.8 (18.3) & $\begin{array}{l}60.9 \\
(21.0)\end{array}$ & $\begin{array}{l}65.8 \\
(18.0)\end{array}$ \\
\hline SF & $\begin{array}{l}33.3 \\
(43.0)\end{array}$ & $\begin{array}{l}28.2 \\
38.5\end{array}$ & $\begin{array}{l}63.3 \\
(25.1)\end{array}$ & $\begin{array}{l}61.8 \\
64.8\end{array}$ & $\begin{array}{l}86.9 \\
(17.3)\end{array}$ & $94.3(12.1)$ & $\begin{array}{l}83.3 \\
(22.7)\end{array}$ & $\begin{array}{l}86.2 \\
(19.8)\end{array}$ \\
\hline RE & $\begin{array}{l}33.0 \\
(42.8)\end{array}$ & $\begin{array}{l}27.7 \\
38.2\end{array}$ & $\begin{array}{l}55.8 \\
(47.1)\end{array}$ & $\begin{array}{l}53.0 \\
58.6\end{array}$ & $\begin{array}{l}76.5 \\
(38.5)\end{array}$ & $95.1(20.6)$ & $\begin{array}{l}81.3 \\
(33.0)\end{array}$ & $\begin{array}{l}84.0 \\
(31.7)\end{array}$ \\
\hline MH & $\begin{array}{l}41.4 \\
(23.6)\end{array}$ & $\begin{array}{l}38.6 \\
44.3\end{array}$ & $\begin{array}{l}49.6 \\
(22.1)\end{array}$ & $\begin{array}{l}48.3 \\
50.9\end{array}$ & $\begin{array}{l}72.7 \\
(16.8)\end{array}$ & $81.8(14.7)$ & $\begin{array}{l}74.7 \\
(18.0)\end{array}$ & $\begin{array}{l}77.5 \\
(15.3)\end{array}$ \\
\hline
\end{tabular}


Table 3

Scores of patients and care-givers in PHQ-9, GAD-7, PHQ-15, and PSQI.

\begin{tabular}{|c|c|c|c|c|c|c|c|c|c|}
\hline \multirow[b]{2}{*}{$\begin{array}{l}\text { PHQ- } \\
9\end{array}$} & \multicolumn{3}{|c|}{ Patients } & \multicolumn{3}{|c|}{ Care-givers } & \multicolumn{3}{|c|}{ Normative level } \\
\hline & $\mathrm{n}$ & $\begin{array}{l}\text { Mean } \\
\text { (SD) }\end{array}$ & $95 \% \mathrm{Cl}$ & $\mathrm{n}$ & $\begin{array}{l}\text { Mean } \\
\text { (SD) }\end{array}$ & $\begin{array}{l}95 \% \\
\mathrm{Cl}\end{array}$ & $\mathrm{n}$ & $\begin{array}{l}\text { Mean } \\
\text { (SD) }\end{array}$ & References \\
\hline & 305 & $\begin{array}{l}12.1 \\
(6.5)\end{array}$ & $\begin{array}{l}11.4 \\
12.8\end{array}$ & 1,258 & $9.5(6.8)$ & $\begin{array}{l}9.1, \\
9.9\end{array}$ & 1,003 & $\begin{array}{l}3.3 \\
(4.1)\end{array}$ & 16 \\
\hline $\begin{array}{l}\text { GAD- } \\
7\end{array}$ & 304 & $9.0(6.0)$ & $8.3,9.6$ & 1,256 & $7.7(5.9)$ & $\begin{array}{l}7.4, \\
8.0\end{array}$ & 5,030 & $\begin{array}{l}3.0 \\
(3.4)\end{array}$ & 10 \\
\hline \multirow[t]{2}{*}{$\begin{array}{l}\text { PHQ- } \\
15\end{array}$} & 290 & $\begin{array}{l}10.3 \\
(6.1)\end{array}$ & $\begin{array}{l}9.6 \\
11.0\end{array}$ & 1,194 & $8.1(6.5)$ & $\begin{array}{l}7.6 \\
8.5\end{array}$ & 9,250 & $\begin{array}{l}5.5 \\
(3.9)\end{array}$ & 31 \\
\hline & & & & & & & 5,031 & $\begin{array}{l}3.8 \\
(4.1)\end{array}$ & 32 \\
\hline \multirow[t]{2}{*}{ PSQI } & 286 & $8.5(3.9)$ & $8.0,8.9$ & 1,184 & $6.9(4.0)$ & $\begin{array}{l}6.7, \\
7.2\end{array}$ & 9,284 & $\begin{array}{l}5.0 \\
(3.4)\end{array}$ & 33 \\
\hline & & & & & & & 629 & $\begin{array}{l}4.9 \\
(2.4)\end{array}$ & 13 \\
\hline
\end{tabular}

Further, correlations between PHQ-9, PHQ-15, GAD-7, PSQI, and subscales of SF-36 were analyzed (Table S2). Moreover, the impact of age, disease types, and gender on scores in these tests were analyzed by a general linear model. Relationship (patients or care-givers) only had an impact on the scores of PHQ-15, PSQI, and GH of SF-36. Specifically, patients had a higher score in PHQ-15 than care-givers (difference = 2.541 , adjusted $p=0.004$ ), indicating more severe somatic symptoms. Patients had a higher score in PSQI than care-givers (difference $=1.829$, adjusted $p=0.002$ ), indicating more severe sleeping problems in patients. Patients had a significantly lower score in GH of SF-36 than care-givers (difference $=-11.327$, adjusted $p=0.001$ ), indicating that the disease burden significantly affected the general health of patients. Disease had an impact on the scores of PHQ-9, PHQ-15, GAD-7, PSQI, and subscales of SF-36 (Table S3). Generally speaking, poor health, anxiety, depression, somatization, and sleeping problems were more severe in patients and care-givers of more severe diseases (e.g., DMD, hemophilia, Dravet) or undiagnosed.

\section{Discussion}

Delayed diagnosis and misdiagnosis is common and can lead to delayed and improper treatment, as well as the irreversible progression of the disease [20]. As a result, unnecessary tests and treatments are often conducted, resulting in significant cost to patients and the healthcare system [19]. A previous study in 2013 reported that it took 5-7 years and 2-3 misdiagnoses in the USA and UK [21]. Interestingly, the duration between onset and diagnosis in China was 1.4 years, and there were only 1.8 misdiagnoses. This may be because of the increased application of newborn screening over the years in China [22]. It 
may be also because social media has increased avenues for relevant information and communication between patients. One major reason for the difficulty in diagnosis is the limited rare disease awareness among patients, families, and physicians. Similar to a previous study in Europe [23], as believed by patients and care-givers in this study, physicians did not have sufficient awareness and knowledge about rare diseases. A recent study among physicians in China also showed a lack of rare disease awareness [24]. Therefore, there is a critical need to include rare disease content in medical education and training. Further, a Chinese information hub of rare diseases was suggested to provide reliable, up-to-date, and 'peer-reviewed' information and guidance. As shown in this study, the majority of patients and care-givers were most interested in information about treatment. Orphan drug development is always expensive and time-consuming, ultimately affecting patients' access to new treatments. Witnessing the success of orphan drug acts in other countries $[25,26]$, there was high support for an orphan drug act in China. Another relevant factor is the low medical insurance coverage, significantly affecting the viability of orphan drugs in the Chinese market. This not only affects the orphan drug development in China, but also affects the import of orphan drugs from abroad. Based on the aforementioned results and discussion, key recommendations that outline top priorities that the policymakers in China should consider are listed as follows:

1. Pass an Orphan Drug Act to stimulate orphan drug development;

2. Official definition or suggested threshold of rare diseases;

3. Improve rare disease awareness among medical professionals and the general public;

4. Improve the medical insurance coverage of rare diseases;

5. Improve the availability and affordability of prenatal screening, newborn screening, and genetic counseling;

6. Prevent discrimination against rare disease patients in education and employment;

7. Accelerate in importing orphan drugs.

\section{Conclusions}

This is the first large-scale study that quantitatively investigates the current status of rare disease patients in China. This study identifies poor health status, depression, somatization, anxiety, and sleeping issues among both patients and care-givers through standardized test, highlighting the need of psychological and medical support. Also, this study also observes difficulties in social life, education, and employment, as well as financial burden. More importantly, the most urgent and critical need of these patients are treatment/orphan drugs. Therefore, a list of action items is recommended to the policymakers, which include legislating an orphan drug act, raising rare disease awareness, and preventing discrimination.

\section{List Of Abbreviations}


National Organization for Rare Disorders (NORD), European Organization for Rare Diseases (EURORDIS), Canadian Organization for Rare Diseases (CORD)

\section{Declarations}

\section{Ethics approval and consent to participate}

The study was approved by the Institutional Ethics Committee of the Guangzhou Medical University, China. All interviewees signed the informed consent and agreed to participated this study voluntarily.

\section{Consent for publication}

Not applicable

\section{Availability of data and materials}

The raw data are not publicly available due to the agreement between the investigators and the participants.

\section{Competing interests}

The authors declare that they have no competing interests.

\section{Funding}

Dr. Xuefeng Li is sponsored by National Natural Science Foundation of China $(81972204,81702327)$, Natural Science Foundation of Guangdong Province (2019A1515011097), Innovation Program of Shenzhen (Grant No. JCYJ20180508165208399), Science and Technology Planning Project of Guangzhou (201904010089), China Postdoctoral Science Foundation: 2018M640834, 2019T120756, the grant from the State Key Lab of Respiratory Disease, Guangzhou Medical University (SKLRD-Z-202002), and the 111 Project (D18010) from the Ministry of Education of China. All other coauthors did not receive any specific grant from funding agencies in the public, commercial, or not-for-profit sectors.

\section{Authors' contributions}

Conceptualization, Resources: X. Li, M. Liu, L Ou. Methodology, Investigation, Formal analysis: B. Li, X. Zhang, S. Zhang, Z. Lu, J. Zhang, J. Zhou. Project Administration: X. Li, L. Ou. Corresponding author, Supervision, Data Curation: L. Ou. The author(s) read and approved the final manuscript.

\section{Acknowledgments}

We are grateful to the patients and their families, who showed great support during the studies. We thank the supervising pediatricians and general practitioners for their cooperation and their support. 


\section{References}

[1] Pariser AR, Gahl WA. Important role of translational science in rare disease innovation, discovery, and drug development. J Gen Intern Med 2014; 29: S804-S807.

[2] Rare diseases - World Health Organization.

https://www.who.int/medicines/areas/priority_medicines/Ch6_19Rare.pdf?ua=1 (accessed 10 August 2020).

[3] Rajasimha HK, Shirol PB, Ramamoorthy P, Hedge M, Barde S, Chandru V, et al. Organization for rare diseases India (ORDI)-addressing the challenges and opportunities for the Indian rare diseases' community. Genet Res (Camb) 2014; 96: e009.

[4] Melnikova I. Rare diseases and orphan drugs. Nat Rev Drug Discov 2012; 11(4): 267-268.

[5] Global Genes. RARE Facts. https://globalgenes.org/rare-facts/ (accessed 10 August 2020).

[6] Schadewald A, Kimball E, Ou L. Coping Strategies, Stress, and Support Needs in Caregivers of Children with Mucopolysaccharidosis. JIMD Rep 2018; 42: 89-97.

[7] Song P, He J, Li F, Jin C. Innovative measures to combat rare diseases in China: The national rare diseases registry system, larger-scale clinical cohort studies, and studies in combination with precision medicine research. Intractable Rare Dis Res 2017; 6: 1-5.

[8] Ware JE Jr, Sherbourne CD. The MOS 36-item short-form health survey (SF-36). I. Conceptual framework and item selection. Med Care 1992; 30(6): 473-483.

[9] Buysse DJ, Reynolds CF 3rd, Monk TH, Berman SR, Kupfer DJ. The Pittsburgh Sleep Quality Index: a new instrument for psychiatric practice and research. Psychiatry Res 1989; 28(2): 193-213.

[10] Löwe B, Decker O, Müller S, Brähler E, Schellberg D, Herzog W, et al. Validation and standardization of the Generalized Anxiety Disorder Screener (GAD-7) in the general population. Med Care 2008; 46(3): 266274.

[11] Kroenke K, Spitzer RL, Williams JB. The PHQ-9: validity of a brief depression severity measure. J Gen Intern Med 2001; 16(9): 606-613.

[12] Spitzer RL, Kroenke K, Williams JB, Löwe B. A brief measure for assessing generalized anxiety disorder: the GAD-7. Arch Intern Med 2006; 166(10): 1092-1097.

[13] Guo S, Sun W, Liu C, Wu S. Structural Validity of the Pittsburgh Sleep Quality Index in Chinese Undergraduate Students. Front Psychol 2016; 7: 1126.

[14] Zhang Y, Qu B, Lun SS, Guo Y, Liu J. The 36-item short form health survey: reliability and validity in Chinese medical students. Int J Med Sci 2012; 9(7): 521-526. 
[15] Li L, Wang HM, Shen Y. Chinese SF-36 Health Survey: translation, cultural adaptation, validation, and normalisation. J Epidemiol Community Health 2003; 57(4): 259-263.

[16] Wang W, Bian Q, Zhao Y, Li X, Wang W, Du J, et al. Reliability and validity of the Chinese version of the Patient Health Questionnaire (PHQ-9) in the general population. Gen Hosp Psychiatry 2014; 36(5): 539544.

[17] Tong X, An D, McGonigal A, Park SP, Zhou D. Validation of the Generalized Anxiety Disorder-7 (GAD-7) among Chinese people with epilepsy. Epilepsy Res 2016; 120: 31-36.

[18] Forman J, Taruscio D, Llera VA, Barrera LA, Coté TR, Edfjäll C, et al. The need for worldwide policy and action plans for rare diseases. Acta Paediatr 2012; 101(8): 805-807.

[19] The Voice of 12,000 Patients.

https://www.eurordis.org/IMG/pdf/voice_12000_patients/EURORDISCARE_FULLBOOKr.pdf (accessed 10 August 10, 2020).

[20] Communication from the Commission to the European Parliament.

https://ec.europa.eu/health/ph_threats/non_com/docs/rare_com_en.pdf (accessed 10 August 10, 2020).

[21] Rare Disease Impact Report. https://globalgenes.org/wp-content/uploads/2013/04/ShireReport1.pdf (accessed 10 August 10, 2020).

[22] Li X, Lu Z, Zhang J, Zhang X, Zhang S, Zhou J, Li B, Ou L. The urgent need to empower rare disease organizations in China: an interview-based study. 2020 August. DOI: 10.21203/rs.3.rs-57453/v1

[23] Estudio ENSERio. https://enfermedades-raras.org/images/stories/documentos/Estudio_ENSERio.pdf (accessed 10 August 2020).

[24] Li X, Zhang X, Zhang S, Lu Z, Zhang J, Zhou J, Li B, Ou L. Rare disease awareness and perspectives of physicians in China: a questionnaire-based study. 2020 August. DOI: 10.21203/rs.3.rs-65651/v1

[25] Orphan Drug Act of 1983. https://www.govinfo.gov/content/pkg/STATUTE-96/pdf/STATUTE-96Pg2049.pdf (accessed 10 August 2020).

[26] Groft SC. Rare diseases research: expanding collaborative translational research opportunities. Chest 2013; 144(1): 16-23.

[27] Liang XY, Nie SF, Qu KY, Peng XX, Wei S, Zhu GB, et al. Evaluation of health-related quality of life among hypertensive patients in a rural area, PR China. J Hum Hypertens 2006; 20(3): 227-229.

[28] Wang R, Wu C, Zhao Y, Yan X, Ma X, Wu M, et al. Health related quality of life measured by SF-36: a population-based study in Shanghai, China. BMC Public Health 2008; 8: 292. 
[29] Ware JE, Snow KK, Kosinski M, Gandek B. SF-36 Health Survey Manual and Interpretation Guide. New England Medical Center: Boston, MA, 1993.

[30] Hopman WM, Towheed T, Anastassiades T, Tenenhouse A, Poliquin S, Berger C, et al. Canadian normative data for the SF-36 health survey. Canadian Multicentre Osteoporosis Study Research Group. CMAJ 2000; 163(3): 265-271.

[31] Hinz A, Ernst J, Glaesmer H, Brähler E, Rauscher FG, Petrowski K, et al. Frequency of somatic symptoms in the general population: Normative values for the Patient Health Questionnaire-15 (PHQ-15). J Psychosom Res 2017; 96: 27-31.

[32] Kocalevent RD, Hinz A, Brähler E. Standardization of a screening instrument (PHQ-15) for somatization syndromes in the general population. BMC Psychiatry 2013; 13: 91.

[33] Hinz A, Glaesmer H, Brähler E, Löffler M, Engel C, Enzenbach C, et al. Sleep quality in the general population: psychometric properties of the Pittsburgh Sleep Quality Index, derived from a German community sample of 9284 people. Sleep Med 2017; 30: 57-63.

\section{Figures}

A

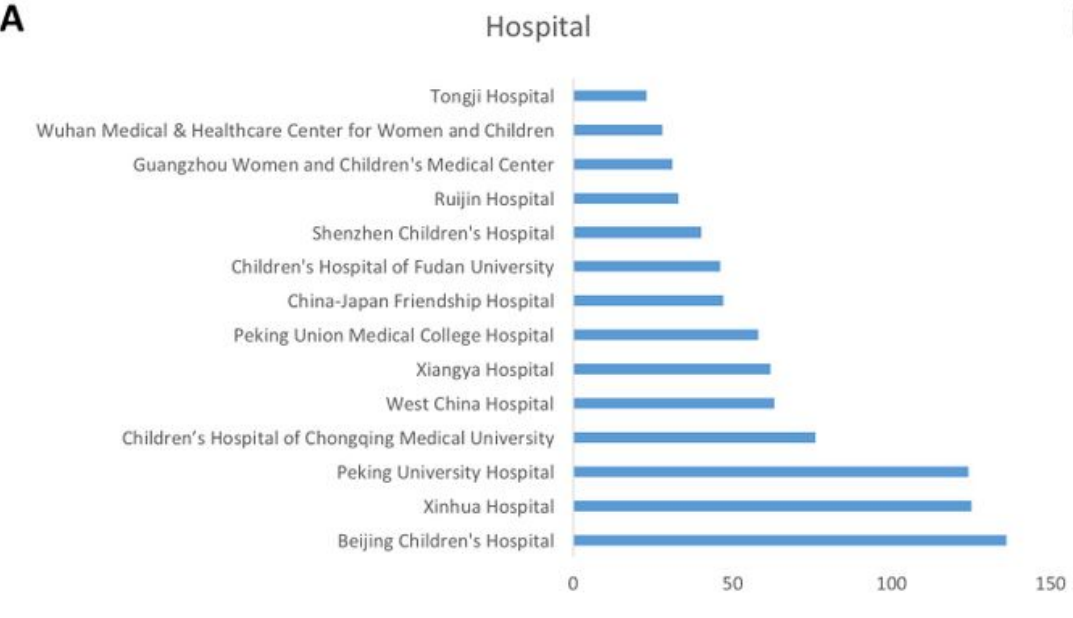

C

Meaning of diagnosis

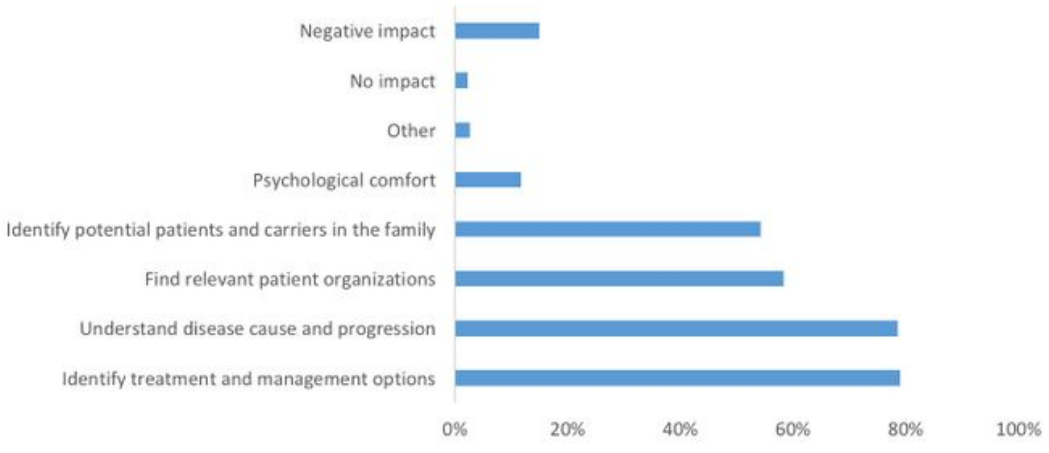

B

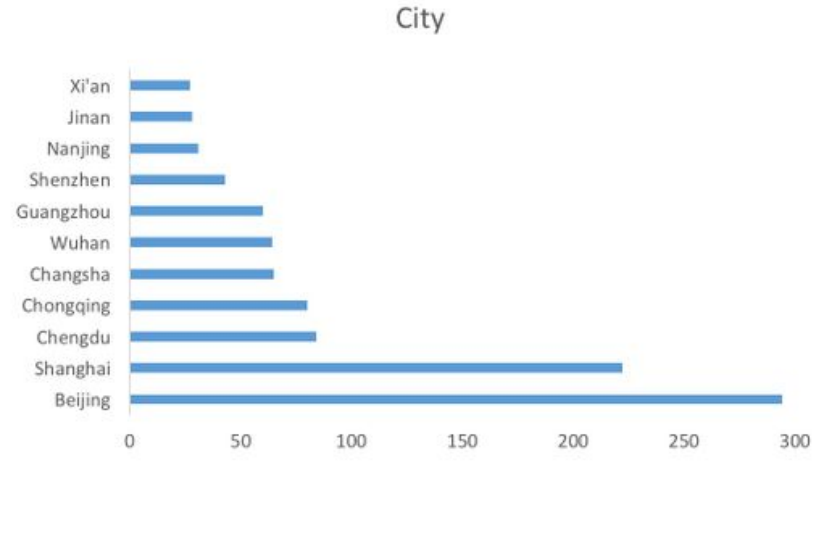

D

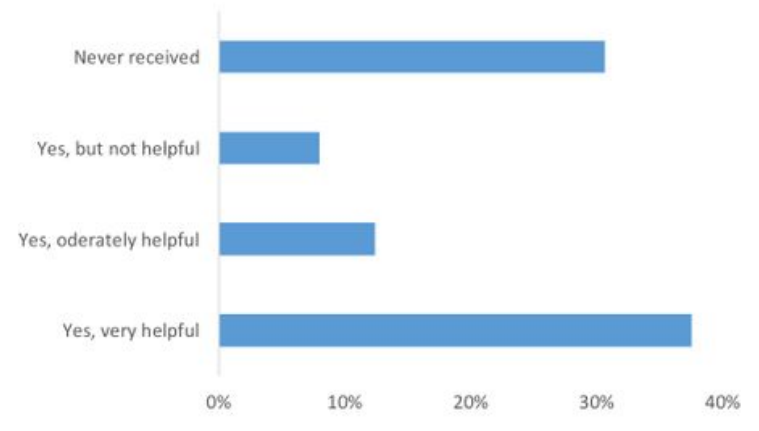

Figure 1 
Information about diagnosis. (A) A list of hospitals where the most patients in this study were diagnosed. (B) A list of cities where the most patients in this study were diagnosed. (C) The meaning of diagnosis to patients and care-givers. (D) The information about genetic counseling.

A

Availability of orphan drugs

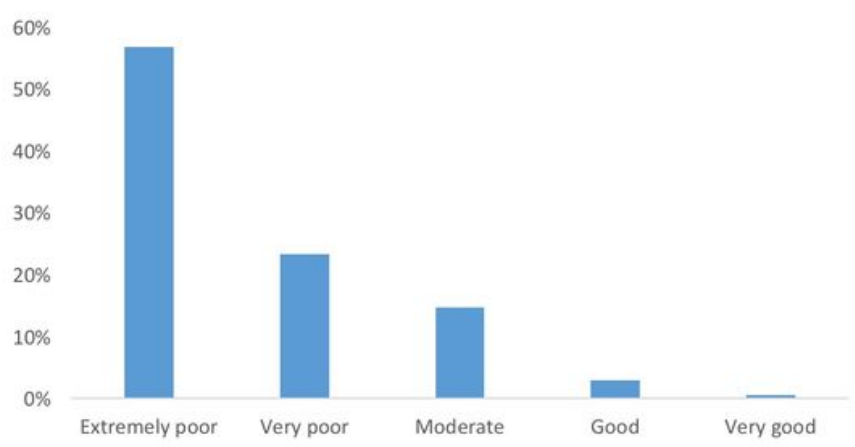

C

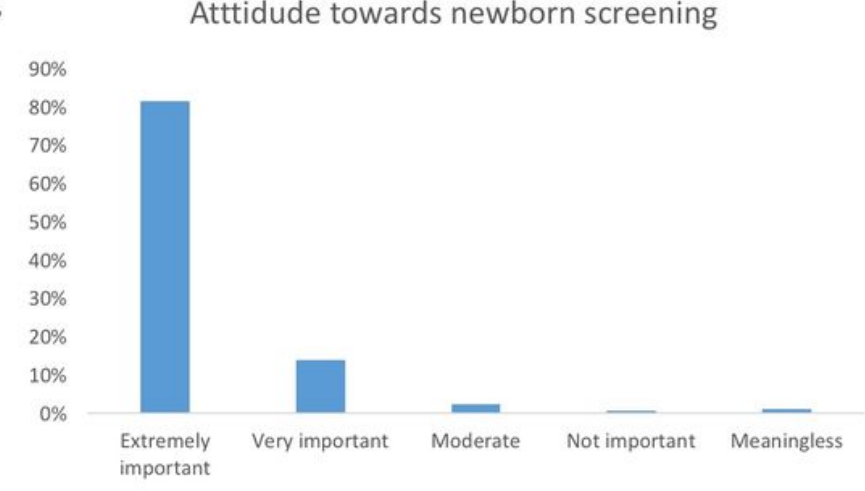

B

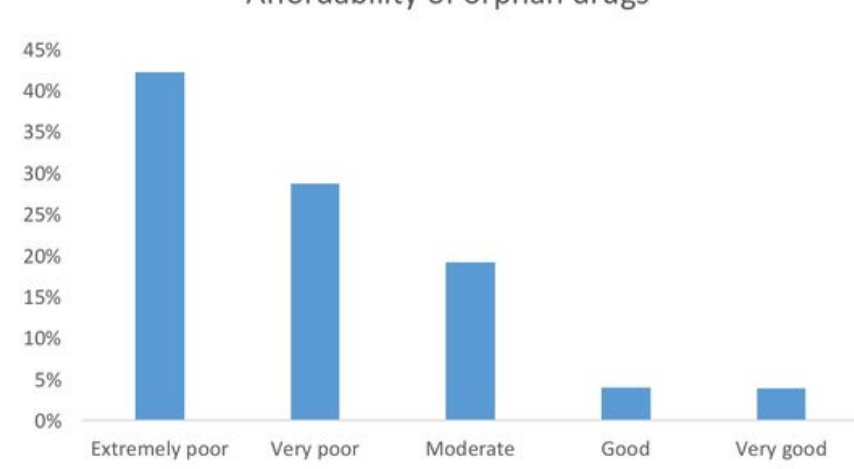

D

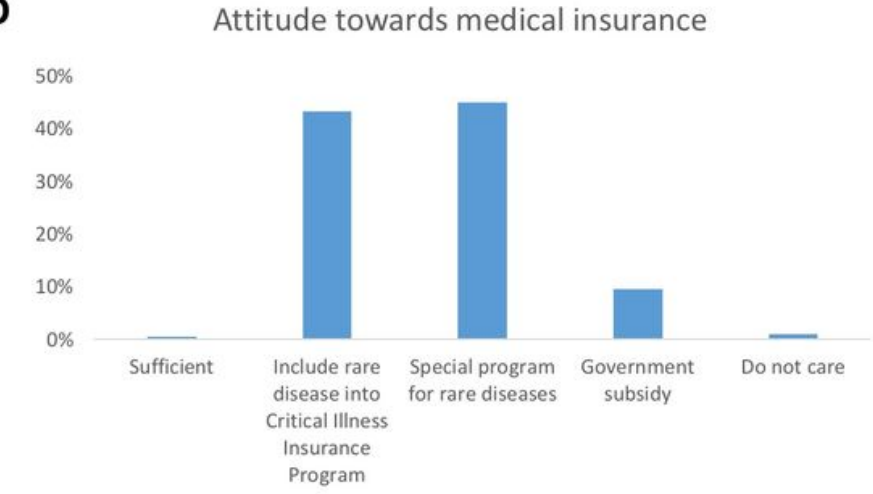

Figure 2

Attitude of patients and care-givers towards orphan drugs, medical insurance, and newborn screening.

\section{Supplementary Files}

This is a list of supplementary files associated with this preprint. Click to download.

- Supplementaryfiles.docx 